\title{
Agronomic
}

Journal

\section{QUALIDADE FISIOLÓGICA DE SEMENTES DE SOJA SUBMETIDAS A DOSES DO INOCULANTE Bradyrhizobium japonicum}

\author{
PHYSIOLOGICAL QUALITY OF SOYBEAN SEEDS SUBMITTED TO INOCULATING \\ RATES Bradyrhizobium japonicum
}

Mirian Nomura ${ }^{1}$; Gabriel Guedes Franco Barbosa ${ }^{2}$; Carlos Henrique de Lima e Silva ${ }^{3}$; Estevam Matheus Costa $^{3}$; Matheus Vinicius Abadia Ventura4; Muriel Silva Vilarinho ${ }^{5}$; Leandro Spíndola Pereira ${ }^{6}$

\footnotetext{
${ }^{1}$ Doutoranda em Agronomia na Universidade Federal de Uberlândia -miriannomura@gmail.com

${ }^{2}$ Agrônomo pela Universidade do Estado de Minas Gerais.

${ }^{3}$ Mestrando em Ciêcias Agrárias - Agronomia no Instituto Federal Goiano, Campus Rio Verde.

${ }^{4}$ Doutorando em Ciêcias Agrárias - Agronomia no Instituto Federal Goiano, Campus Rio Verde.

${ }^{5}$ Universidade do Estado de Minas Gerais

${ }^{6}$ Agronomia no Instituto Federal Goiano, Campus Rio Verde.
}

\section{Info}

Recebido: 01/2019

Publicado: 06/2019

ISSN: 2595-6906

\section{Palavras-Chave}

Bactérias promotoras de crescimento, germinação, Glycine max, vigor.

Keywords:

Growth promoting bacteria, germination, Glycine max, vigor

\section{Resumo}

A inoculação de sementes de soja com bactérias fixadoras de nitrogênio tem grande importância para o cultivo dessa espécie, dispensando a necessidade de adubação nitrogenada. Objetivou-se avaliar a influência de diferentes doses do inoculante à base de Bradyrhizobium japonicum na qualidade fisiológica das sementes de soja. 0 experimento foi desenvolvido no Laboratório de Tecnologia de Sementes na Universidade Estadual de Minas Gerais. Utilizaram-se as sementes da variedade Nidera NS 7300 IPRO e o inoculante Grap Nod. O delineamento experimental foi inteiramente casualizado (DIC), com cinco tratamentos e quatro repetições. As variáveis analisadas foram: porcentagem de germinação, comprimento de parte aérea, comprimento de radícula e peso de plântulas. Os dados obtidos foram submetidos à análise de variância pelo teste $\mathrm{F}$ e as médias comparadas pelo teste de Tukey $(\mathrm{P} \leq 0,05)$. As diferentes doses do inoculante à base de Bradyrhizobium japonicum não apresentaram diferenças significativas entre si para as variáveis analisadas.

\section{Abstract}

The inoculation of soybean seeds with nitrogen - fixing bacteria is of great importance for the cultivation of this species, avoiding the need for nitrogen fertilization. The objective of this study was to evaluate the influence of different rates of Bradyrhizobium japonicum inoculum on the physiological quality of soybean seeds. The experiment was developed at the Seed Technology Laboratory at the State University of Minas Gerais. Seeds of the Nidera NS 7300 IPRO variety and the Grap Nod inoculum were used. The experimental design was completely randomized (DIC), with five treatments and four replications. The analyzed variables were: percentage of germination, shoot length, root length and seedling weight. The data were submitted to analysis of variance by the $\mathrm{F}$ test and the means compared by the Tukey test $(\mathrm{P} \leq 0.05)$. The different doses of the inoculant based on Bradyrhizobium japonicum did not present significant differences between them for the analyzed variables.. 


\section{INTRODUÇÃO}

O cultivo da Soja (Glycine max) é considerado uma das principais atividades econômicas no mercado mundial, sendo uma das principais culturas consumidas e produzidas mundialmente, ficando atrás do milho, trigo e arroz. (HIRAKURI e LAZZAROTTO, 2014). No mercado brasileiro a soja possui grande relevância, sendo a principal commodity agrícola, tornando o Brasil o segundo maior produtor do mundo, com uma produção estimada de $3.168 \mathrm{~kg} / \mathrm{ha}$, ocupando uma área cultivada de 35,818 milhões de hectares (CONAB, 2019). Devido aos avanços nas pesquisas e tecnologias pode-se observar que essa espécie é amplamente difundida e adaptada em todo país (EMBRAPA, 2013).

Assim como nas demais culturas de interesse econômico, o plantio da soja requer diversas exigências para que haja uma maior produtividade. Dentre essas exigências encontra-se a prática de inoculação de microrganismos capazes de realizar fixação biológica de nitrogênio (FBN) (NONATO, 2016). O processo de FBN ocorre naturalmente sendo realizado por microrganismos, como bactérias presentes no solo, que captam o nitrogênio do ar e o disponibiliza para as plantas (MACHADO, 2013), além de promover melhorias no sistema radicular. O cultivo de soja no Brasil, tornou-se viável principalmente pela associação de bactérias do gênero Bradyrbizobium em nodular as raízes da soja (VARGAS et al., 1993).

O nitrogênio possui papel fundamental para o crescimento e desenvolvimento da soja, sendo metabolizado e usado para a formação de aminoácidos, proteínas, lipídeos, dentre outras funções HUNGRIA et al., 2001). Estima-se que para produzir $1.000 \mathrm{~kg}$ de grãos de soja, são necessários aproximadamente $80 \mathrm{~kg}$ de $\mathrm{N} / \mathrm{ha}$. (HUNGRIA et al., 2012).

A utilização de inoculantes à base de Bradyrbizobium spp, promove uma economia anual em adubos nitrogenados por volta de 3,2 bilhões de dólares (FAGAN et al., 2007). Estudos apontam que a inoculação de microrganismos fixadores de nitrogênio à base de Bradyrbizobium spp., têm viabilizado o cultivo de soja no Brasil, obtendo maior produtividade de grãos, quando comparados a plantios onde não ocorreu a inoculação (ALVES et al., 2003).

A técnica de inoculação à base de microrganismos, como o Bradyrbizobium spp. promove diversos benefícios para o cultivo da soja, desde a economia com fertilizantes minerais até a promoção de melhorias morfológicas nas raízes, proporcionando melhor absorção de água e nutrientes, possibilitando o melhor desenvolvimento da planta durante seu ciclo e a formação de grãos de qualidade.

Objetivou-se avaliar a qualidade fisiológica das sementes de soja submetidas a diferentes doses de inoculante à base de Bradyrbizobium japonicum.

\section{MATERIAL E MÉTODOS}

O experimento foi conduzido no Laboratório de Sementes da Universidade Estadual de Minas Gerais, situado no município de Ituiutaba, Minas Gerais (1858'08”' S 49²7’54” O) entre os meses de outubro e novembro de 2018. A cultivar de soja escolhida para a realização do experimento consiste na NS 7300 IPRO da empresa Nidera Sementes, de ciclo médio e ampla adaptação geográfica e época de cultivo. 
O inoculante utilizado no experimento foi o Grap Nod de natureza física líquida, contendo duas estirpes, sendo elas: SEMIA 5079 e SEMIA 5080 que garantem $5 \times 10^{9} \quad \mathrm{UFC} / \mathrm{ml}$. Sua composição é à base de bactérias Bradyrbizobium japonicum com dose de $100 \mathrm{~mL}$ para $50 \mathrm{Kg}$ de sementes.

O delineamento experimental foi $\mathrm{em}$ Blocos Inteiramente Casualizados, contendo cinco tratamentos e quatro repetições. Os tratamentos foram constituídos por 5 doses de inoculante: $0 \mathrm{ml}$ $50 \mathrm{~kg}^{-1}$ de sementes; $50 \mathrm{ml} 50 \mathrm{~kg}^{-1}$ de sementes; 75 $\mathrm{ml} 50 \mathrm{~kg}^{-1}$ de sementes; $100 \mathrm{ml} 50 \mathrm{~kg}^{-1}$ de sementes e $150 \mathrm{ml} 50 \mathrm{~kg}^{-1}$ de sementes. Foram avaliadas as seguintes variáveis resposta:

Germinação (G): As sementes foram colocadas para germinar em substrato de papel de germinação ("germitest"), previamente umedecido em água utilizando-se 2,5 vezes a massa do papel seco, e mantido a temperatura de $25^{\circ} \mathrm{C} . \mathrm{Na}$ semeadura realizou-se o tratamento das sementes com carbendazim + tiram, na dose de 0,3 e $0,7 \mathrm{~g}$ de ingrediente ativo por quilo de semente. As avaliações foram realizadas aos cinco e oito dias após a implantação do teste, e os resultados expressos em porcentagem de plântulas normais, conforme as Regras para Analise de Sementes (Brasil, 2009).

Massa de matéria seca (MMS): foram utilizadas dez plântulas por unidade experimental, da quais foram extraídos os cotilédones, e em seguida acondicionadas em sacos de papel Kraft e colocadas em estufa com circulação de ar à $80^{\circ} \mathrm{C}$ por 24 horas. Após a secagem foi realizada a pesagem e os resultados expressos em mg por plântula (VIEIRA; KRZYZANOWSKI, 1999).
Comprimento Total de Plântulas: Foram utilizadas quatro subamostras de 15 plântulas para cada tratamento. As sementes foram semeadas em rolos de papel "germitest", umedecido com água destilada, na proporção de 2,5 vezes em relação ao peso seco do papel, e mantidas em germinador regulado a $25^{\circ} \mathrm{C}$ durante sete dias. O comprimento da radícula foi determinado entre a ponta da raiz principal até o colo da plântula, enquanto que o comprimento da plântula foi determinado da região do colo até o meristema apical. As avaliações foram realizadas no oitavo dia após a semeadura e os resultados expressos em centímetros $(\mathrm{cm})$.

Os dados foram submetidos à análise de variância, e as médias comparadas pelo Teste de Tukey ( $\mathrm{P} \leq 0,05)$, com o auxílio programa estatístico SISVAR.

\section{RESULTADOS E DISCUSSÃO}

Observa-se na Tabela 1 que os resultados evidenciam que não houve diferença significativa na germinação de sementes de soja e no comprimento de radícula submetido a diferentes doses do inoculante.

Resultados semelhantes foram observados por ZUFFO (2016), em estudo das bactérias Azospirillum brasilense e Bradyrbizobium japonicum inoculadas de forma individual ou associadas, onde o autor não encontrou diferenças significativas entre os parâmetros agronômicos avaliados. Os mesmos resultados foram observados por BULEGON et al. (2014), onde os autores concluíram que bactérias Bradyrbizobium japonicum não se mostraram eficientes na germinação e desenvolvimento inicial das plântulas. 
Tabela 1. Germinação (G) e comprimento de radícula (CR) de soja inoculada com bactérias Bradyrbizobium japonicum em diferentes doses

\begin{tabular}{ccc}
\hline Tratamentos & G $(\%)$ & CR $(\mathrm{cm})$ \\
\hline 150 & $84 \mathrm{a}$ & $3,0 \mathrm{a}$ \\
100 & $76 \mathrm{a}$ & $3,0 \mathrm{a}$ \\
75 & $79 \mathrm{a}$ & $3,0 \mathrm{a}$ \\
50 & $84 \mathrm{a}$ & $3,0 \mathrm{a}$ \\
0 & $88 \mathrm{a}$ & $3,0 \mathrm{a}$ \\
\hline DMS & 14.49 & 0 \\
CV $(\%)$ & 8.07 & 0 \\
\hline
\end{tabular}

Médias seguidas das mesmas letras nas colunas, não diferem entre si pelo teste de Tukey ( $\mathrm{p} \leq 0,05)$; DMS: diferença mínima significativa; cv: coeficiente de variação.

Uma possível explicação para esses significativas entre si (Tabela 2). Esse resultado resultados deve-se a baixa eficiência dos corrobora com o estudo desenvolvido por inoculantes a base de Bradyrbizobium japonicum na Bullegon et al. (2014), onde realizou-se a fase de germinação das sementes e na expansão da radícula, podendo ter resultados mais satisfatórios a partir do desenvolvimento da planta (ZILLI et al., 2006). inoculação de Bradyrhizobium japonicum (Simbiose Nod $\circledast$ ) em cultivares TURBO, no qual os autores não constataram diferenças no comprimento da parte aérea das plantas de soja.

Para as variáveis, comprimento da parte aérea e peso de plântulas, não houve diferenças

Tabela 2. Comprimento de parte aérea (CA) e massa de matéria seca (MMS) de soja, inoculadas com bactérias Bradyrbizobium japonicum em diferentes doses

\begin{tabular}{ccc}
\hline Tratamentos & CA $(\mathrm{cm})$ & MMS $(\mathrm{g})$ \\
\hline 150 & $3,5 \mathrm{a}$ & $16,6 \mathrm{a}$ \\
100 & $4,0 \mathrm{a}$ & $16,4 \mathrm{a}$ \\
75 & $4,7 \mathrm{a}$ & $18,9 \mathrm{a}$ \\
50 & $4,3 \mathrm{a}$ & $18,1 \mathrm{a}$ \\
0 & $4,7 \mathrm{a}$ & $18,2 \mathrm{a}$ \\
\hline DMS & 1.89 & 4.81 \\
CV $(\%)$ & 20.38 & 12.48 \\
\hline
\end{tabular}

Médias seguidas das mesmas letras nas colunas, não diferem entre si pelo teste de Tukey ( $\mathrm{p} \leq 0,05)$; DMS: diferença mínima significativa; cv: coeficiente de variação.

Diante do exposto, pressupõe-se que as bactérias Bradyrbizobium japonicum não possuem benefícios diretos para o processo de germinação e desenvolvimento de plântulas na cultura da soja, visto que as mesmas irão se manifestar na presença do nitrogênio presente na atmosfera, ou seja, quando as plantas já tiveram adaptadas no ambiente de cultivo para realizar o processo de fixação de nitrogênio. De acordo com HUNGRIA et al. (2013), a inoculação da soja com bactérias do 
gênero Bradyrbizobium na cultura da soja resultou em um aumento de 8,4\% no rendimento de grãos.

\section{CONCLUSÕES}

As doses de Bradyrbizobium japonicum não influenciaram na qualidade fisiológica das sementes de soja. Atenta-se para a não eficiência desses microrganismos na germinação de sementes e no desenvolvimento das plântulas, porém, nos estádios mais avançados, a inoculação possui papel fundamental para um melhor desenvolvimento da cultura.

\section{REFERÊNCIAS BIBLIOGRÁFICAS}

ALVES, Bruno JR; BODDEY, Robert M.; URQUIAGA, Segundo. The success of BNF in soybean in Brazil. Plant and soil, v. 252, n. 1, p. 1-9, 2003.

BRASIL. Ministério da Agricultura Pecuária e Abastecimento. Secretaria de Defesa Agropecuária. Regras para análise de sementes. Brasília: MAPA, 2009a. 395p.

BULEGON, L. G.; KLEIN, J.; RAMPIM, L.; GUIMARÃES, V. F.; BATTISTUS, A. G.; KESTRING, D. Desenvolvimento inicial de plântulas de soja inoculadas e Co-inoculadas com Azospirillum brasilense e Bradyrhizobium japonicum. Journal of Agronomic Sciences, Umuarama, v.3, n.1, p.26-37, 2014.

COMPANHIA

NACIONAL

DE ABASTECIMENTO (CONAB). Soja, Safra
2018/2019. Sexto Levantamento, março 2019.

EMBRAPA. EMPRESA BRASILEIRA DE PESQUISA AGROPECUÁRIA. Tecnologias de produção de soja - região central do Brasil. 2013. (Sistemas de Produção/Embrapa Soja, n.16) - Londrina: Embrapa Soja, p.265, 2013.

FAGAN, E. B.; MEDEIROS, S. L. P.; MANFRON, P. A.; CASAROLI, D.; SIMOM, J.; DOURADO, N. D.; MULLER, L. Fisiologia da fixação biológica do nitrogênio em soja - Revisão. Revista da FZVA, vol. 14, n. 1, p. 89-106, 2007.

HIRAKURI, M. H. LAZZAROTTO, J. J. O agronegócio da soja nos contextos mundial e brasileiro. Londrina-PR: Embrapa Soja, 2014. 70p.

HUNGRIA, M.; NOGUEIRA, M. A.; ARAUJO, R. S. Tecnologia de Coinoculação da Soja com Bradyrhizobium e Azospirillum: incrementos no rendimento com sustentabilidade e baixo custo. Resumos da XXXIII Reunião de Pesquisa de Soja da Região Central do Brasil. Londrina-PR, 2013.

HUNGRIA, M., R. J. Campo, e I. C. Mendes. 2001. Fixação biológica do nitrogênio na cultura da soja. Embrapa Soja: Circular Técnica. Londrina, BR. 
HUNGRIA, M.; RUBENS, J. C.; NOGUEIRA, M. A. A pesquisa em Fixação Biológica do Nitrogênio na Embrapa Soja: passado, presente e perspectivas futuras. Anais. XVI Relare. Londrina-PR, 2012.

MACHADO, L. Inoculação de sementes de soja - um fator determinante no sucesso da lavoura. Universidade Federal de Lavras, 2013. Disponível em: http://www.anpii.org.br/inoculacaodesementes-de-soja-um-fatordeterminanteno-sucesso-da-lavoura. Acesso em: 02 de Abril 2019.

NONATO, J. J. Nutrição, fisiologia e produtividade de soja inoculada com Azospirillum brasilense e reguladores vegetais. 2016. 79p. Dissertação (Mestrado em produção vegetal) Faculdade de Agronomia, Universidade Estadual do Centro-Oeste, Guarapuava - PR.

VARGAS, M. A. T.; MENDES, I. C.; SUHET, A. R.; PERES, J. R. R. Fixação biológica do nitrogênio. In: ARANTES, N. E.; SOUZA, P. I. M. Cultura da soja nos cerrados. Piracicaba: POTAFÓS, 1993.

VIEIRA, R. D; KRZYZANOWISKI, F. C. Teste de condutividade elétrica. In: KRZYZANOWISKI, F. C; VIEIRA, R. D; FRANÇA NETO, J. B. (Ed). Vigor de sementes: conceitos e testes. Londrina, ABRATES, 1999, cap. 4, p. 1-26.

ZILLI, J. E.; MARSON, L. C.; CAMPO, R. J.; GIANLUPPI, V.; HUNGRIA, M.; SMIDERLE, O. J. Avaliação da fixação biológica de nitrogênio na soja em áreas de primeiro cultivo no cerrado de Roraima. Embrapa: Roraima, 2006. 9 p. (Comunicado Técnico, 20).

ZUFFO, A. M. Aplicações de Azospirillum brasilense na cultura da soja. 2016. 101 p. Tese (Doutorado e Agronomia/Fitotecnia) Universidade Federal de Lavras, Lavras 2016. 